\title{
A STUDY AND ANALYSIS OF THE EVOLUTIONARY COURSE OF PERSIAN LANGUAGE AND LITERATURE TEXTBOOKS IN IRANIAN SCHOOLS
}

\author{
Reza Eskandari ${ }^{1}$ \\ Ali Sarvar Yaghoubi ${ }^{2}$ \\ Abbas Ali Vafaie ${ }^{3}$
}

\begin{abstract}
Persian Language and Literature Textbooks The Ministry of Education is one of the widest audience and most influential media in transferring knowledge and skills to the next generation of the country and, given the large number of audiences, has a great role to play in student learning. As the science progresses, the mission of the authors of textbooks will be doubled. Persian language books with a new look will be the precursor of the modernist generation. These books must be in tune with the needs of their audience for dynamism. This essay analyzes and critiques the developments of Persian language textbooks and literature after the Islamic Revolution in the linguistic
\end{abstract} and intellectual realms, perhaps to pave the way for the authors to follow.

Keywords: Textbooks, Persian Literature, Islamic Revolution, Modern Needs, Intellectual and Linguistic Realms.

\section{Introduction}

We have long been asked why today's college students and graduates are unable to write. Is it a problem by them not to have learned linguistic and literary teachings well or is it due to inadequate textbooks? Certainly, this problem is rooted in early education, but teachers, authors, families, and administrative systems also contribute to this failure.

\footnotetext{
${ }^{1}$ Ph.D. Student, Department of Persian Language and Literature, Arak Branch, Islamic Azad University, Arak, Iran. Email: Eskandari54mehdi@gmail.com.

${ }^{2}$ Assistant Professor, Department of Persian Language and Literature, Arak Branch, Islamic Azad University, Arak, Iran. Corresponding Author Email: Raaymand92@gmail.com.

${ }^{3}$ Professor, Department of Persian Language and Literature, Allameh Tabataba'i University, Tehran, Iran. Email : A_a_vafaie@yahoo.com.
} 
Textbooks have always been the most important and effective means of communication and knowledge transfer. With the compulsion in education, textbooks have become more orderly and consistent. The books were relatively in tune with the social conditions and developments of the community as well as the students' moods. Among the textbooks, Persian language and literature books and have a greater share in the transfer of general concepts and the exchange and understanding of specialized courses. authors, considering the influential and valuable role of Persian books, goals such as acquisition of linguistic skills, rules of cognition, as well as familiarity with past and contemporary poem and prose texts have been considered. While investigating developments in Persian language and literature textbooks, this study is aimed at correcting deficiencies and reinforcing valuable Persian educational textbooks in future editions.

\section{Statement of the problem}

High school students are introduced to Persian language and literature textbooks with examples of the poem and prose of past and contemporary literary elders as well as linguistics, grammar, writing, and spelling. Paying attention to the needs and interests of the students in the compilation of the textbooks is essential for the achievement of the goals of the Persian textbooks. The main problem with Persian textbooks in the past and partly in the recent period is the lack of attention to age and gender differences of the audience. We have repeatedly seen the poem, which was a decade of high school education, the same for elementary school in the recent period.

Persian books are the first window through which every student looks at the wonderful world of science and art and has an impact on the audience's intellectual and artistic foundations. Students are expected to achieve goals such as mental refreshment, nurturing culture, studying, strenghtening understanding, criticism and analysis by studying Persian books. The motivation of this survey from the study of Persian textbooks in the last three decades, in addition to their interest in literary and linguistic topics, is directly related to these topics while teaching.

By bringing up topics of grammar that are at the forefront of grammar, teachers are challenged in the 
classroom and this motivates the student towards the linguistic realms of the book. This problem is to the extent that each year the book is made available to students with a minor editing compared to the previous year. The authors' view of grammatical issues is also a structural one. Although not completely deviated from the traditional grammar, grammatical topics can now be considered as unique in student textbooks.

The lessons of writing are mainly written in an inductive way with the help of sample analysis. Paying attention to the practical aspects and enhancing the writing skills have been important goals of the authors, but unfortunately due to lack of time and lack of impact on students' academic destiny, the goals of the book are not fulfilled. In spelling, students become familiar with the rules of proper writing, skill in the correct use of words, and aesthetics, writing, and spelling. Spelling tips are also included during the lessons to teach students to become familiar with the theoretical rules of spelling.

Since everything at the beginning is problematic, Persian textbooks also have some of the strengths and weaknesses that this study will explore in order to be considered when necessary. The subject of this research is a topic that the author is constantly involved with, and perhaps teaching these books in the classroom has been the author's main motivation. Therefore, the purpose of this study is that among the four topics of Persian linguistics, grammar, writing, and spelling books, the grammar section has received the most attention from teachers of the Persian literature and elsewhere has been less sensitive because it has had little background in the past. Have not more attention is given to the grammar part because it differs greatly from traditional and past grammatical topics. It has not been easy for many scribes and protesters to adopt grammatical topics in a new way. The purpose of this research is to assist the authors of Persian language and literature books in developing new topics in new ways. In addition, it has attempted to address textbook challenges to eliminate those barriers and problems.

\section{1-1. Research Background}

Considering the important role of Persian language and literature textbooks in transferring culture and art to future generations of the country, 
numerous researches have been done in this regard, including the following articles:

1- The article "Introducing and Criticizing the Book of Compounded Proposals: Making the Names - the Verb" by Parivash Safa and Zahra Zandi Moghaddam, Special Letter to the Academy (Winter 2008), no.9.

2- "A Look at the Translation of Contemporary Persian Literary Grammar" by Mohsen Shojaei, Special Letter to the Academy (winter), no. 8

3- The article "Persian Book and Writing (2) Criticism " by Sima Beignejad, Journal of Persian Literature, Fall 1977, No. 32.

But the way they were criticized, as mentioned,was selective and less voluminous. This study attempts to address the important role of Persian textbooks in a larger volume in the linguistic, literary and intellectual fields.

\section{1-2. Research Questions}

1- How successful have the Farsi textbooks been for different students' familiarity with the phenomenon of language and its role in social relations?

2. To what extent can appropriate teaching methods be effective in achieving the goals of Persian language books?

3. How effective are modern teaching strategies in addressing challenging textbooks?

\section{Discussion}

\section{2-1. History of Textbooks of Persian} Language and Literature in Iran

From the sixth century onwards, the writing of moral books on advice for children expanded. "Books such as the Nasserian Ethics, the Morality of Khawajah Nasir al-Din al Tusi, Bahr al-Favaid by an Unknown Author, Tohfeh al-Muluk in the Rites of Ali Esfahani, al-Adab al-Wajiz Lelvalad al-Saqir, which Khawajah Nasir al-Din al Tusi translated into Arabic. This book is attributed to Ibn al- Muqaffa (Mohammadi and Qa'ini: p. 2/116-122).

Schools were considered to be important teaching circles during the Qajar era. In the school, they were taught the religious sciences first, and then the literary sciences were simple and elementary. Graduates of the Qajar school were divided into three categories: "If the child was the son of a merchant or marketer, his goal was to study the Qur'an and learn the script and 
essay and to prepare himself for writing calculations to benefit it later. In such a situation, his education was limited to Golestan and Nassab al-Sabian's books, Tavvassol and jami-i-Abbasi and Siaq (a type of Arabic numerals and acronyms) and sometimes the Hafiz Divan and the Saadi bustan. Whenever a child was from a lowly and disadvantaged group, his father was interested that his child to finish reading the Qur'an or at least learn special suras from most small and simple suras. The third group was those who wanted to go to higher education, but not too many, who went through the first stages and sought higher education, and these were the children of emirs, Mostofian, courtieres, scholars or individuals. Who wanted to become clergy or mujtahids, and these people entered their schools or theological school of the time, where the subjects were different from those of the home school and they followed professors to study abroad or domestically. " (Qasemi Pouya: pp. 49-50).

\section{Homeschooling materials} expanded over time, and home school graduates in addition to learn theology, memorized poetry and studied ethical books. In the Qajar period, the level of difficulty and consistency of the text increased more than in previous periods. Qajar students read Jami-i alMuqaddimat,Hashieh by Mullah Abdullah,Nasek al-Tawarikh ,Sana'i and Rumi Divan, and even in mathematics Khulasat al hisab by Baha'i. "Following the issuance of the constitutional decree, a number of Persian language teachers produced books that introduced students to excerpts from the pleasant texts of Persian literature and anecdotes and new stories" (Taher Ahmadi: p. 2-4).

The first textbooks emerged with the establishment of Dar al-Fonun and the compulsory teaching of elementary education. After years of teaching at Dar al-Fonun, foreign teachers have been able to train students who can make official textbooks using Dar al-Fonun's classes. The first Dar alFonun school textbooks included various mathematical sciences, geographical biology, history, language, and literature. After the advent of private schools, textbook teaching was based on the views of school teachers. Grammar books by Mirza Habib Esfahani, Iran's brief history of Mohammad Ali Foroughi and the history of al-Mujam fe al-asar alMujam's by Fadlallah Hosseini are examples of books taught in these schools. "With the occupation of Iran by 
the Allies in World War II and its continuation until 4 years, the government lost the ability to continue publishing textbooks. As a result, printing houses and publishers on the one hand and experienced authors and teachers on the other hand, authored and published various books. The Ministry of Culture permitted all books to be published that appeared to be in accordance with the curriculum. This open space and free competition in authoring and publishing textbooks has led to chaos (especially in high school books) and has lowered textbooks both quantitatively and qualitatively "(Saffarpour: p. 3).

After the establishment of the Textbooks Organization in 1942, the textbooks were compiled and coordinated in a coordinated manner for all levels of education. The educational system of the country has changed three times since 1946. Textbooks have undergone many changes as a result of this transformation. After the Islamic Revolution, textbooks in Persian language and literature were no exception.

\section{2-2. Intellectual realm}

469

\section{2 -2-1. Content evolution of Persian}

\section{language and literature textbooks} after the Islamic Revolution of Iran

One of the strengths of the books of Persian language and literature after the Islamic Revolution is the intellectual division of the book based on a particular order. This discipline of thought is also evident in recent books. In some cases, of course, the question arises for the student as to how, for example, the Ashura literature differs from the resistance literature, or what the two differ from the literature of the Islamic Revolution. Perhaps it was better that sections such as war literature, the Ashura movement, and the literature of the Islamic Revolution come under the heading of sustainable literature.

The good practice adopted in the compilation of educational textbooks of the last decade is a change in the content of textbooks. The textbooks after the Islamic Revolution of Iran have changed significantly in terms of content in the past. Valuable subjects, such as the culture of martyrdom, resistance and endurance and world literature before the revolution did not contribute to textbooks. When we speak of resistance literature, this section can also include texts from other countries such as the 
Chilean, Palestinian, and Lebanese revolutions.

\section{Post-revolutionary textbooks} attempted to remind students of the days of the Islamic Revolution and the years of imposed war, given the political and social developments of the society. Therefore, textbook authors have made a significant contribution to acquainting the audience with examples of the poem and prose literature of the Islamic Revolution. In addition to writings and poems, textbook images have been effective in inducing the concepts of martyrdom and resistance.

One of the problems with Persian textbooks in the past was the lack of impact on students. The selection of poem and prose literature of the past is very popular and students should not be disconnected from the past literature of this land, but attention to individual differences and audience preferences is one of the main criteria of textbook writing. Dr. Kamal Ahmadinejad from the author of textbooks has an interview that is remarkable:

"I have seen old books that first were authored by masters like Forouzanfar and Homayi. They chose texts that were of their own accord and liked them much. I do the same now if I want to choose the text, but the text chosen for the youth must be exciting, and we can make great use of our past literature. The textbook should not be personal taste and education should be considered (Ahmadinejad, p. 8).

A comprehensive look at the Persian language textbooks and literature shows that each book has some of the lessons of the past. Two decades ago, we had a selection of world literature and sustainable literature in textbooks, which we have in the last decade from the same textual subjects. Occasionally repetition of the subject occurs in a grade and a textbook. For example, in the third grade of high school literature published in 2010, the eighth lesson contains text from the history of Bayhaqi and the ninth grade contaains the art of Bayhaqi writing, by giving some examples from the history of Bayhaqi. It would have been better to summarize these two lessons in one lesson, and after studying the art of writing Abulfazl Beihaghi in the form of "learn", we made student to research the stylistic and intellectual attributes of the selected text from this historian.

One of the friends said: "It seems that the main purpose of teaching Persian literature in Iranian schools is to 
deter students from whatever literature is. I do not know whether or not this is the intention. But we see the result is nothing else. Students' attention to Persian literature is decreasing year by year and their knowledge of the rules of the language and literature of the country is diminished. (Natalie Khanlery: p. 4)

Primary students are familiar with some of the religious, moral, political, and social doctrines in the Read. In fact, Persian textbooks at the beginning of the academic year provide students with concepts such as knowledge, dating, the role of water in human life, the importance of warm family focus and then social environments such as school, mosque and park

Primary Persian books are not only in the field of literature and art, but also serve the purpose of serving other sciences, and this task may somewhat reduce the pleasure of the literary of Persian books.

\section{2-2-2. Relationship of governance with} the educational institution

" In all societies, there is an interactive relationship between the institution of education and governance, and because of this relationship, "the government strives to advance its goals and to educate generations in accordance with its political interests and goals. In examining the institution of education, the social ideology that governs society and its practices of authority must be studied. Because the educational goals of different societies are based on the goals and ideology of sovereignty. Hence, the foundation of the institution of education becomes a tool to accomplish thethe goals of sovereignty "(Hamedi: p. 1).

\section{2-2-3. Elementary Persian books in} the past

In the past,the Persian Book of the Early Period contained pleasant poems and texts that aimed to teach Persian alphabet, reading, spelling and acquaintance with ancient literature. Past authors of Persian textbooks had no interest in cultivating children's creativity. As the global patterns of education evolved, the authors of new books adopted new educational principles. The style of Persian books is divided into four classes: listening, reading, writing and speaking. Of course, if the poetry is carefully and scientifically selected, it can enrich children's literature. 


\section{2-2-4. Resistance Literature in}

\section{Textbooks}

The category of sustainability literature is an emerging category that has been introduced in textbooks for the last three decades, with the aim of conveying a culture of self-sacrifice and testimony to futurists who have not understood the victory of the revolution and the era of imposed war. Textbooks along with other media have the task of acquainting the third generation of the revolution with the values of the revolution. Literature textbooks at all levels of education offer lessons on the centrality of the course of the Islamic Revolution and the bravery of the Islamic warriors during the eight-year war. Some of the lessons also deal with Ashura culture, the role of women in the victory of the Islamic Revolution and the period of the imposed war, the manner of resistance in the Arab Muslim countries as well as in Latin America. The areas of sustainability literature in textbooks are based on the three axes of Ashura, womanhood and epic myths.

\section{2-3. Linguistic territory}

\section{2-3-1. Language development and its} importance
472

The transformation and change of the language of every society is in line with the social changes of that society. Some believe that to persuade and expand the Persian language one must refine the language and prevent foreign words from entering. The focus of attention on the Persian language was strong during the Qajar era, and many intellectuals believed that foreign and even neighboring words should be avoided in order to protect Persian words. Preservation of the Persian language led to the formation of the Academy of Language. Many intellectuals were concerned about the destruction of the Persian language and believed that the destruction of the language would lead to the destruction of culture.

\section{2-3-2. Grammar}

As the science and social developments began to grow, language changed. Certainly, traditional methods cannot meet the scientific needs of students' day. Revising the teaching of grammatical topics does not diminish the value of the work of past instructors such as Mirza Habib Esfahani, Mirza Abdul Azim Garib and Bahar. Traditional grammarians in the grammatical 
examples have also used past poem and prose texts, while scholars view the grammatical issues of poem and prose in the context of historical grammar.The greats such as Khanleri and Khayyampour authored a new, relatively scientific approach.

In the early decades of the Islamic Revolution, Gholamreza Arjang and Ali Ashraf Sadeghi wrote grammar in the field of culture and literature that was far from the traditional grammar, which had a great impact on the writing of the books of eighties. Eighties books came closer to the order of constructionism, though these books were not without weaknesses. For example, most of the students were confused about word and lexeme. Until 2016,the secondary school textbooks were revised by removing disagreements in grammar issues. However, in some cases this revision was accompanied by changes and modifications, for example, prior to the year; they did not find "collective signs" and "indefinite sign" in word construction. The abovementioned signs were changed in eleventh grade, published 2016. This dichotomy and disagreement led to the elimination of word construction from the grammatical point of view.
473

Another disadvantage of

Persian textbooks is the inadequacy of some topics. For example in the discussion of supplementation, students cannot distinguish verb supplementation from other types of supplementation. They say that any noun that comes after preposition is complementary, while the best way to distinguish between complementary types is to pay attention to the verb. The association of grammatical topics with linguistic fundamentals may have been difficult for some literary educators, as linguistic topics in the field of literature at Iranian universities are not very important.

\section{2-4. The importance of writing in textbooks}

Writing and attention to essay time has long been a subject of literature classes. Education in our schools is more reserved and of no practical application. If a student kept writing rules and tried to score, he wouldn't have to worry about his inability to write an office letter because he had only memorized an office letter at school and we never asked him to write it. "Literature, in essence, that is, creativity; the teacher first asks the student to write the meaning of the book's poems, while the mission of the 
literature is to teach thought, to increase the power of understanding. It is in this lesson that we have to teach thinking "(Zulfiqari: p. 1-2).

We have seen many students give their writings and poems to the literature teacher for evaluation. Here, the teacher can guide them to reading by strengthening their writing skills. "We have a lesson called essay whose task is to teach instruction, but this lesson is not primarily related to Persian language lessons; secondly, it is not related to other student learning and therefore frozen in a number of formats of subjects; and thirdly It does not provide the student with the opportunity to write Farsi, and each of these three attributes has adverse effects "(Masoumi Hamadani: p. 206). "Reading just like falling in love is by no means a passive act. It requires a lot of mental, emotional and physical energy. Man must devote all his intellectual powers to the recreation of his analytic world, in the fullest and clearest possible way, within himself. It is essential to have a definite speed of reading to enable this to work. (Miller: p. 141)

Writing classes are generally not an attempt at writing, and writing hours are generally spent teaching other courses, while learning to write is superior to teaching grammar. Writing requires a lot of reading, but if we know all the rules of grammar but have not read books in history, fiction, writing, or travel logs, writing is not going to happen. The most common writing errors office correcpendence derive from the lack of practice in the fields of linguisties and writing script,marking and technicak rules of schools.

Grammar should be for writing, not for purpose. The purpose is writing and the grammar of the instrument. In the past, our literary greats did not know grammar, but they could be the best creator of prose and poem by studying the works of the ancestors of the Creator. Of course, understanding the prerequisites of a grammer is necessary to write, but it goes into the details to depart from the original purpose of writing. The existential philosophy of writing lessons for many educators is still unclear. Maybe if they were aware of the importance of writing, the statistical community of those who are averse to writing would not be expanded.

Writing textbooks is a step towards being a writer while our graduates are not able to put their personal needs and desires on paper. Of 
course, there are some who write purposefully and find their way through reading good books in adolescence and youth. "In the writing of this youthful outburst one has to think carefully. Learn to say less and think more. The author is more in conversation with himself and with what he is dealing with. The author does not want, and should not, in the short term convince anyone of what he believes. In the first place, the author must persuade himself to do something while struggling within himself. "(Dolatabadi: p. 2)

Perhaps one of the reasons the society has no interest in writing, is its necessity. One needs to say more than just to communicate with others, so writing is not like public speaking. Text is more valuable than speech. The prerequisite for literary creation is the element of imagination, eloquence and rhetoric. But in an office letter, the purpose of messaging is. In office letters, careful use of the correct words is important. Office letters represent the author's scientific and social base.

Sometimes in Persian language and literature textbooks which teach their readers how to write and speak, we encounter typographical or scientific errors for reasons of haste, carelessness, and lack of typography, such as:

- Type "Zal" instead of "Zag" in Fifth Grade of Primary Persian Page 91 Print 96

- No marking: "Strength": Feed, Thunder, Force. Persian Twelfth grade Page 169 Print 97

- Adjective is in conformity to noun and adhering to Arabic rules: "Shari'a rulings". Persian Twelfth grade Page 171 Print 97

- " Disregard for writing and essay causes our students to be passive readers; that is, to close their eyes and to read. Neither attempt to share the experience that the writers had, nor recognize what they have read. Teaching Language and Literature in our education system neither teaches the student the understanding or enjoyment of literature nor teaches him / her the skills of language use; especially, he / she does not teach writing. (Masoumi Hamadani: p. 206).

\section{2-5. The contribution of stylistics in} Persian language and literature textbooks

Considering the developments of textbooks after the Islamic Revolution, the concept of stylistics and 
the history of literature has appeared in different forms in textbooks. Textbooks on the history of literature and stylistics for the humanities were presented at the second, third, and fourth grades. These books were divided into literary periods based on the prominent figures of each period, from pre-Rudaki to the age of awakening. The main difference between the books of this period and the previous periods was the history of world literature, which first introduced the European literary schools to classics, romanticism, realism, naturalism, symbolism and surrealism. Finally, there was a section devoted to Arabic literature that provided an overview of the early works of Islam to new achievements in Arabic literature.

At the pre-university grade of humanities, stylistics consisted of Persian poem and prose styles, referring to the literary and intellectual characteristics of the Khorasani, Iraqi, Indian, returning and contemporary styles. It is titled Science and Techniques. The stylistics in recent period textbooks is not much different from the previous ones, and it may be said that recent period books have nothing new to the stylistic aspect of the past and are in fact a repetition or quotation of the contents of the history of literature books of earlier eras.

As we know, there is a wonderful interplay between stylistics and the history of literature. The division of literary periods on the basis of literary indices forgets the historical aspect of the book. Studying the style of poetry and the writing of literary indices in historical eras, erases the shortcomings of the debate. Another flaw in the history of literature is the lack of attention to female faces in poetry and writing. A significant portion of the country's students are female students. They have the right to know the role of women poets or writers in the literature of the country and the world.

\section{2-6. History of Literature in Public} Books of Recent Period

In the Persian textbook of the current system of education, the history of literature at the secondary level is of little importance. The proper nouns section has been deleted from the end of the books. For the authors, perhaps it is not necessary to bring the proper nouns to a low audience, while the proper nouns is to guide the students in the research. How is it that in the primary and secondary level of Persian language 
books, we have proper nouns and then at the high school books this part is deleted.

In previous textbooks, the student, in addition to the proper nouns, was given a brief introduction to the creator of each chapter by studying the The proper nouns of the lessons or the beginning earnings of each chapter, but omitting the descriptions of the lessons in the new course and even In some cases they do not give the name of the work or the creator of a text, which we give examples here:

1- The Twelfth grade, Covenant of Friendship from Lotfali Asghar

2- Twenty-second Bahman by Sayyed Ziaeddin Shafie'i Eleventh Grade

2 - " Morning without you" poem by "Kaiser Aminpour" eleventh grade

4- "Kaveh Dadkhah" by "Gholamhossein Yousefi" Eleventh Grade

2- "Haidari attack" poem br " Bazel Mashhadi " eleventh grade

6- "Khosrow" from "Abdul Hussein Wejdani"

\section{Conclusion:}

According to the analysis and analysis of the school textbooks of
Persian language and literature, the following results were obtained:

1- Looking at the history of the evolution of Persian language books and literature in schools, the necessity of updating Persian books was emphasized.

2- The educational content of Persian language books and literature should be in line with the social developments and the increasing development of the communication media.

3. The difficulty of our graduates in writing is due to memorizing of the lessons

4- Requires the ability to read texts promptly, be proficient in the field of expression, as well as write essential and common texts, recognize and utilize modern and applied teaching methods.

5. Every language and literature needs a strong grammar and strong support in the name of the history of literature for its dynamism and development to be able to reach its peak with the help of these two wings.

\section{References:}

Ahmadinejad, Kamel (2014). Interview with Textbook Authors (2), Journal of Persian Language and Literature 
Department, Academy of Sciences, March 2014, No. 8.

Big Nejad, Sima (1979), "Persian Book and Writing Criticism (2)", Persian Language and Literature Quarterly, Fall 1977, No. 32.

Hamedi, Zahra (2015). Foundations of the Ideology of Sovereignty and its Influence on Textbooks in the Early Pahlavi Era, Iranian History Publishing.

Dolatabadi, Mahmood (2010). W , Writing, Tehran: Cheshmeh Publishing, Third Edition.

Zolfaghari, Hassan (2016). The Impact of Educational System Reform on Promotion of Persian Language and Literature, Journal of Persian Language and Literature Department, Academy of Sciences, February 2016, No. 30.

Shojaee, Mohsen (2012). "A Look at the Translation of Contemporary Persian Literary Grammar," Special Letter to the Academy (Grammar), Winter 2, no.

Safa, Parivash and Zahra Zandi Moghadam (2013). "Introducing and Criticizing the Book of Composite
Sentences: Making Verbs", Special Issue of the Academy Letter (Grammar), Winter 2, no.

Safarpour, Abdol Rahman (2015). History of Textbooks in Iran from the Establishment of Dar-al-Fonoun to the Present, Journal of Persian Language and Literature Department, Academy of Sciences, July 2015, No. 11.

Taher Ahmadi, Mahmoud (2006). The Pioneers of Writing Textbooks of Persian Education in the Constitutional Age, Master Treasurer, Summer 2006, No. 62.

Qasemi, Pouya (1377). New Schools in the Qajar Period, Tehran: University Publication Center.

Mohammadi, Hadi and Zohreh Ghaini (2001). History of Iranian Children's Literature, Tehran, Chista Publishing.

Masoumi Hamadani (1996). Reading and Writing, Selected Articles in Knowledge Publishing, Tehran: Center for Publications. 
Periódico do Núcleo de Estudos e Pesquisas sobre Gênero e Direito Centro de Ciências Jurídicas - Universidade Federal da Paraíba V. 8 - No 05 - Ano 2019 ISSN | 2179-7137 | http://periodicos.ufpb.br/ojs2/index.php/ged/index

Miller, Joseph Heilson (2004). What is

Literature? Translated by: Soheil

Sommii, Tehran, Phoenix.

Natel Khanlari, Parviz (2015). Teaching

Persian Literature, Educational Bulletin

of the Faculty of Persian Language and

Literature, No. 9 